\title{
EEN EN ANDER OVER DE KOEBOES ${ }^{1}$ ).
}

G. J. van Dongen unternimmt es, sich des längeren mit meinen Veröffentlichungen über einen kurzen Aufenthalt meinerseits bei den Kubu auf Sumatra, auseinanderzusetzen. Die Publikationen, auf welche van Dongen Bezug nimmt, sind: „Kubu und Jakudn (Jakun) als Protomalayen". Mitteilungen der A. G. Wien, 1926, ein Aufsatz von 9 Seiten und die letzten Kapitel (S. 218-255) aus meinem Buch: „Orang-Utan”. „Bei den Urwaldmenschen Malayas und Sumatras", Brockhaus 1928.

Unmöglich kann ich jetzt auf van Dongen's umfassende Schrift (100 Seiten) näher eingehen, die es sich zum Ziel gesetzt hat, meine Auffassung von der Nichtprimitivität der Kubu, die ich vorerst in grossen Linien in den eben angeführten Publikationen skizzierte, in einer etwas ungewöhnlichen Form abzutun. Das hätte ein neuerliches Einleben in die malayisch-sumatranischen Probleme zur Voraussetzung, aus denen mich die zweijährige Forschungsreise zu den Pygmäen Zentral-Afrikas völlig herausgerissen hatte. Jedenfalls wird sie die Grundlage zu einer eingehenden Erörterung bieten, wenn ich künftighin in der Lage sein werde, die wissenschaftliche Publikation über meine Forschung in Asien in Angriff zu nehmen. Auf einzelne Anwürfe und Aussetzungen aber möchte ich jetzt schon eine kurze Erwiderung beziehungsweise Aufklärung geben.

Wenn sich van Dongen der Mühe unterziehen wollte, meinen an erster Stelle zitierten Aufsatz gründlich zu prüfen, so würde er finden, dass ich den Beweis für die Nichtprimitivität der Kubu, wie sie am hervorregendsten Dr. B. Hagen verteidigt, aus einem Vergleich mit den Jakudn auf Malakka ziehe. Gerade das Methodische der Arbeit sollte beachtet werden. Aus diesem Grunde allein befasste ich mich mit Hagen's Buch und nicht mit den Publikationen van Dongen's und anderer, obwohl sich Hagen auf dessen Bericht von den Ridan Kubu stiitzt. Auch war mir damals nur das Buch Hagen's

1) Eine vorläufige Erwiedering von Dr. Paul Schebesta auf G. J. van Dongen's: Een en ander over de Koeboes, naar aanleiding van Prof. P. P. Schebesta's Publicaties over dit Volk. (Bijdragen tot de Taal-, Land- en Volkenkunde van Nẹderlandsch-Indië. Deel 88. S. 519-619.) 
gut bekannt. Dieses Buch allein war auch die Veranlassung des Ab. stechers, den ich nach Sumatra machte, um zu prüfen, ob der Eindruck, den ich aus der Lektüre dieses Buches gewann, zutreffe, nämlich, dass Jakudn (unter denen ich gerade weilte) und Kubu kulturell und rassenhaft ein Volk seien. Die Bestätigung war eine glänzende, worauf ich im ersten Eifer den Bericht nach Europa sandte, in dem ich Jakudn und Kubu als Protomalayen vereinigte und den Gang des Beweises skizzierte. Damit war gegeben, dass ich zu der angeblichen Primitivität der Kubu, wie sie Hagen verteidigte, Stellung nehmen musste. Meine Gedankengänge, gestützt auf Aussagen der Kubu, sind in der Schrift angedeutet, doch finden sie bei van Dongen keinen Anklang.

Van Dongen mag wohl Recht haben, dass ich die Schrift vielleicht anders abgefasst hätte, wäre mir bekannt gewesen, dass Hagen schon tot war. Es ist dies aber mit ein Beweis dafür, dass ich mich vor meiner Ausreise nach Hinterindien in gar keiner Weise mit den Kubu beschäftigte und auch nicht im Sinn hatte, die Kubu aufzusuchen, sonst hätte ich die Kubu-Literatur allseitig studiert.

Es scheint tatsächlich, dass ich mein Versprechen van Dongen gegenüber, ihn über meine Publikationen über die Kubuprobleme zu unterrichten, nicht eingelöst habe. Es kann dies nur Vergesslichkeit meinerseits gewesen sein, denn ich hatte keinen Grund, die in Djambi mit dem damaligen Residenten van Dongen gemachte Verbindung abzubrechen; vielmehr war ich ihm dankbar, dass er mich über manche Fragen in loyaler Weise aufklärte. Während einer zweimaligen Zusammenkunft am 11. und 12. Juni hatte ich Gelegenheit mit ihm verschiedene Kubuprobleme zu besprechen, wobei wir auch eingehender über die Publikation Dr. B. Hagen's über die Kubu sprachen. Dabei machte mich van Dongen in liebenswürdiger Weise auf einzelne seiner Berichte über die Kubu, die mir unbekannt waren, aufmerksam.

Es ist mir unbegreiflich, wie van Dongen einleitend schreiben kann, dass ich die Reise nach Sumatra unternommen hätte, sozusagen um die Glaubwürdigkeit der Forschungen Dr. B. Hagen's zu prüfen. Die Sumatra-Reise war ursprünglich garnicht in meinem Plan und niemand in Wien hatte Ursache, an Hagen's Darstellung der Kubu zu zweifeln. Vielmehr war der Grund einzig jener, den ich in meiner erstgenannten Schrift, also schon im Juli 1925, von Malakka angebe: „Als ich im Anschluss an meine sechzehnmonatigen Forschungen unter den Negrito auf Malakka und Siam auch die Jakudn zu stu- 
dieren begann, so überraschte mich die $̈$ Ähnlichkeit ihrer Kultur mit jener der Kubu. Letztere kannte ich zwar nur aus der Literatur. Dies reizte mich natürlich, auch die Kubu aus eigener Anschauung kenneu zu: lernen und die Ähnlichkeit ihrer Kultur mit jener der Jakudn zu prüfen. So unternahm ich denn die Reise in die Gebiete von Palembang und Djambi auf Sumatra, durchquerte dieses Gebiet und besuchte alle erreichbaren Kubuniederlassungen am Bajat, Ulu Lalang. Kandang und Jiu Bahar. Gewiss kann ich keine tiefe Kenntnis der Kubu durch einen dreiwöchigen Aufenthalt unter ihnen für mich in Anspruch nehmen".

Der gereizte Ton der Schrift van Jongen's stammt, soweit ich aus ihr herauslese, daher, dass ich mich nicht mit seinen Ideen, die er mir damals entwickelt hatte, auseinandersetzte und dass er zu glauben scheint, ich nähme seine Beobachtungen über die Ridan Kubu nicht ernst. (cf. S. 616 seiner Schrift) Dazu möchte ich bemerken, dass es mir nie einfällt, die von einem Forscher gemachten Beobachtungen - mag der Forscher welcher Richtung auch immer sein - zu bez.weifeln oder als unglaubwürdig hinzustellen, was ich selbstredend auch von anderen ïber meine Forschungen erwarte. Dass Irrtümer hüben wie drüben möglich sind, wird selbstredend nicht in Abrede gestellt.

Eine andere Angelegenheit ist aber die Stellungnahme zu der Interpretation der gemachten Beobachtungen. Niemand kann mir verwehren, dass ich nach meinen Erfahrungen und meinen Kenntnissen diese so oder anders zu erklären suche, auch wenn sie den Erklärungsversuchen anderer diametral entgegenstehen. Das habe ich denn in meinen beiden Publikationen getan, indem ich auf Grund der Erfahrung bei den Jakudn und Kubu zu der Erkenntnis kam, dass beide Völker ursprünglich ein Volk (Protomalayen) seien. Diese These suchte ich vorläufig zu beweisen und zog dann meine Schlüsse daraus, und der Hauptschluss war eben der, dass die Kubu keine Primitiven (im engeren Sinne) sein können. Bislang hat mich niemand eines anderen belehrt oder gezeigt, dass meine These unhaltbar ist. Van Dongen geht auf meine Gedankengänge nicht direkt ein, sondern entschuldigt sich mit der Unkenntnis der Jakudn. Gerade jetzt, nach dem ich noch die zentralafrikanischen Pygmäen kennen gelernt habe, sehe ich umsoweniger ein, wie man die Kubu unter die „Primitivsten” zu zählen wagt.

Niemals fiel mir aber ein, die gemachten Beobachtungen van Dongen's an den Ridan Kubu zu bezweifeln, wohl aber lehne ich die 
von ihm und anderen gezogenen Schlüsse wegen der zu knappen Bekanntschaft mit diesen Kubu als zu weitgehend ab.

Van Dongen ist durchaus im Irrtum, wenn er meint, dass ich als katholischer Priester unmöglich seine Ansichten und jene von Dr. Hagen akzeptieren könne: „Zijn Roomsch Katholiek priesterschap, waardoor hij zich gebonden voelde aan de inzichten van zijn Kerk, en waarom hij volgens zijn eigen verklaring zich niet met Dr. Hagen's en mijn zienswijze omtrent de oorspronkelijke Koeboes kon vereenigen". Nein, diese Ansichten lehne ich aus durchaus konkreten, wissenschaftlichen Gründen ab, mag van Dongen und wer auch immer behaupten, es geschehe, weil ich angeblich durch irgendwelche katholische Lehrmeinung gebunden sei. Ich kann van Dongen verraten, dass die katholische Kirche betreffs der Kubu gar keine Meinung hat, ich also auch keineswegs irgendwie gebunden war. Ich finde es sonderbar, wie ernste Männer, wie van Dongen es gewiss ist, andere -- seien es auch katholische Priester, denen die Wahrheit mindestens soviel wert ist als jedem anderen auch - so eng beurteilen können.

Sachlich und umfassend werde ich natürlich erst bei einer wissenschaftlichen Darstellung meiner Untersuchungen auf Sumatra in Zusammenhang mit jenen von Malaya auf die Schrift van Dongen's eingehen können, wobei dann selbstredend auch die anderen Publikationen van Dongen's über die Kubu werden berücksichtigt werden und zwar an erster Stelle, denn ich halte ihn ebenso jetzt wie auch früher als den besten Kenner der Kubu, der um ihre Erforschung grosse Verdienste hat. Ergänzungen und Berichtigungen erkenne ich gerne an, denn niemals masste ich mir eine umfassende Kenntnis der Kubu an.

Dass van Dongen aus einem Druckfehler ,Tschawat aus Bambusrinde" anstele ,aus Baumrinde" so viel Aufhebens macht, ist belustigend. Aus vorhergehenden Schilderungen über die malayischen Völker hätte er ersehen können, dass Baumrinde gemeint war.

Ich notierte immer ,,djukur” anstelle von ,kudjur”. Ich erlaube mir van Dongen darauf aufmerksam zu machen, dass die metathesis in einzelnen Dialekten auf Sumatra wie auch unter den Jakudn auf Malaya viel vorkommt. Unter den Mantra besteht sogar eine Sprache, deren Worte regelmäsig durch metathesis gebildet werden.

Ich hoffe, dass van Dongen es zu würdigen wissen wird, wenn ich den Kubuproblemen in Zukunft nur sachlich begegnen möchte.

DR. P. P. Schebesta. 


\section{NASCHRIFT.}

Van den Secretaris van het. Koninklijk Instituut ontving ik bovenstaande „Vorläufige Erwiederung” van Prof. P. P. Schebesta ter kennisneming met de mededeeling, dat mocht ik hieraan een en ander wenschen toe te voegen, het Bestuur bereid is hieraan te voldoen, ofschoon de Bijdragen zich zooveel mogelijk onthouden van polemiek. Voor deze bereidwilligheid bied ik het Bestuur hierbij mijn welgemeenden dank aan.

Naar aanleiding van bovenstaand artikel is het me nu begrijpelijk geworden, hoe Prof. Schebesta er toe gekomen is, zijn „Kubu und Jakudn (Jahun) als Protomalayen" te publiceeren op een wijze zooals dit gebeurd is, en waartegen ik o.m. in mijn laatste Koeboe-verhandeling ben opgekomen. Dat in een publicatie, zóó ,im ersten Eifer” opgesteld, al het neergeschrevene niet precies gewikt en gewogen is, acht ik zeer aannemelijk.

Schrijver verklaart thans, dat het absoluut niet in zijn bedoeling gelegen heeft te twijfelen aan mijn waarnemingen omtrent de RidanKoeboes, alsook dat hij het geschrevene anders zou hebben geredigeerd als hij had geweten, dat Dr. Hagen reeds overleden was. Waren deze omstandigheden mij bekend geweest, dan zou ik mijn laatste Koeboe-verhandeling zeer zeker in een anderen vorm gegoten hebben. Jammer is, dat Prof. Schebesta nu niet tevens even heeft aangestipt, waarom hij Dr. Hagen's theorie op zoo'n vreemde wijze weergaf.

Het is er verre van, dat ik een categorie van personen als de $\mathrm{R}$. K. priesters ervan zou willen betichten, dat zij niet minstens even waarheidslievend zoude zijn als wie ook. Evenmin ging het er in deze om, of de R. K. Kerk zich al dan geen meening omtrent de Koeboes had gevormd, doch wèl om Prof. Schebesta's verklaring, dat hij als R. K. priester niet kon aannemen, dat een volk, i.c. de Koeboes, oorspronkelijk ,religionslos” geweest zoude zijn. In overeenstemming hiermede vermeldt hij op bladz. 242 van zijn „Orang Utan”: „Das Religionsproblem bei den Kubu ist insofern besonders interessant, als man dieses Volk bisweilen als religionslos hinstellte. Wir hätten danach an den Kubu das einzige religionslose Volk auf Gottes weiter Erde. Kein Wunder also, dasz ich diesem Ausnahmevolk besondere Aufmerksamheit zollte", -- terwijl de derde en laatste samenvatting in het slot van zijn „Protomalayen” luidt: „Die Kubu standen niemals auf einem ,,solchem Nullpunkt” der Kulturentwickelung wie es uns Hagen gerne glaubhaft machen möchte, so zwar, das 
sie .... überhaupt frei waren von allen religiösen Ideen und Vorstellungen. Das letzte ist meiner Ansicht nach ein Märchen", - een conclusie, die ik niet anders verwacht had, gegeven de vooropgestelde verklaring. Het kwam er nu maar op aan, welke bewijstrant gevolgd zou worden om tot deze conclusie te komen, en hierop vestigde ik op de tweede bladzijde van mijn laatste Koeboe-verhandeling reeds speciaal de aandacht.

Zeer ten rechte zegt Prof. Schebesta hierboven: „Gerade das Methodische der Arbeit sollte beachtet werden”, en verder: „Meine Gedankengänge, gestützt auf Aussagen der Kubu, sind in der Schrift angedeutet, doch finden sie bei van Dongen keinen Anklang". Juist, en hierom gaat het uitsluitend, dus om de waardeering dezer publicaties van den onderzoeker Schebesta, m. a. w. om de bewijsgronden waarop zijn stellingen steunen, en niet om zijn theses alleen, - en in geen geval om een enghartige of kleinzielige beoordeeling van een zoo hoogstaande categorie van personen als de R. K. geestelijkheid, die hiermede niets heeft uit te staan.

„Gerade jetzt, nachdem ich noch die zentralafrikanischen Pygmäen kennen gelernt habe, sehe ich umsoweniger ein, wie man die Kubu unter die „Primitivsten” zu zählen wagt”. Ja, thans is dit inderdaad niet meer het geval. Daarvoor had Schebesta dit volkje eenige tientallen jaren eerder moeten bezoeken, en zelfs toen zou een vrij kortstondige kennismaking met slechts de meest geciviliseerden onder hen waarschijnlijk ook tot verkeerde conclusies geleid hebben. - In November 1913 ontmoette Mr. W. A. J. M. Waterschoot van der Gracht in de omgeving van het Doewabelas-gebergte van Djambi nog oorspronkelijke Koeboes, voor wie toen rijst nog slechts een door ruilhandel verkrijgbaar luxe-artikel was. (vide zijn interessante mededee-lingen hierover in het tijdschrift van het K. N. A. C. over Maart 1915).

De door Prof. Schebesta bedoelde metathesis in enkele talen of dialecten dier streken zal ik niet ontkennen, doch bij de Koeboes heet een lange speer ,koedjoer” en nooit ,djoekoer”.

Ik kan het niet anders dan ten zeerste waardeeren, dat Prof. Schebesta, met vooropstelling van wederzijdsche goede trouw, de Koeboeproblemen voortaan slechts zakelijk zal behandelen. Het is jammer, dat de geproduceerde schrifturen niet den indruk gegeven hebben, dat een en ander van den beginne af aan reeds in de bedoeling heeft gelegen. -

Scheveningen, April 1932.

G. J. van Dongen. 
